\title{
Paternal Smoking and Birthweight in Shanghai
}

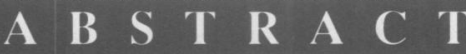

Objectives. Although maternal active smoking has been established to be associated with fetal growth retardation, evidence of an effect of environmental tobacco smoke exposure on birthweight is still limited and inconclusive. This study addressed the relationship between prenatal environmental tobacco smoke exposure and birthweight and fetal growth retardation in Shanghai, China.

Methods. Data on 1785 full-term live-born nomal infants of nonsmoking mothers were used from the Shanghai Birth Defects and Perinatal Death Monitoring conducted between October 1986 and September 1987. Envirommental tobacco smoke exposure was defined as exposure to paternal smoking.

Results. Infants with environmental tobacco smoking exposure were, on average, $30 \mathrm{~g}$ lower in birthweight than nonexposed infants, after adjustment for gestational age, parity, maternal age, and occupation.

Conclusion. Consistent with previous research, this study suggests that environmental tobacco smoking exposure may have a modestly adverse effect on birthweight. (Am J Public Health. 1993;83:207210)

Jun Zhang, MB, and Jennifer M. Ratcliffe, PhD, MSc

\section{Introduction}

China is the largest country in the world in terms of the production and consumption of tobacco. Half of the global increase in tobacco use from 1976 to 1986 occurred in China, and the smoking prevalences are $52 \%$ and $73 \%$ for men 20 through 24 and 25 through 44 years of age, respectively. ${ }^{1}$ The nicotine content of Chinese cigarettes ranges from 0.7 to $1.2 \mathrm{mg}$ and the tar content from 21 to $33 \mathrm{mg}$ per cigarette, and most Chinese cigarettes are unfiltered. In Shanghai, $57 \%$ of men 20 to 39 years of age are smokers. ${ }^{2}$ Most of them smoke 10 to 20 cigarettes per day (very few young people use other types of tobacco products). On the other hand, smoking among women is rare in Shanghai (less than $0.5 \%$ in women aged 20 to 39). ${ }^{2}$ Although it is well established that active smoking during pregnancy is associated with a decrease in birthweight (of an average of 150 to $200 \mathrm{~g}$ ) and an increase in low-birthweight infants, ${ }^{3}$ evidence of an effect of prenatal environmental tobacco smoke exposure on birthweight is still limited and inconclusive. ${ }^{4}$ Our study examined the relationships between environmental tobacco smoke exposure, birthweight, and fetal growth retardation using data from a case-control study of birth defects and perinatal mortality conducted in Shanghai. 5 One of the advantages of these data is that confounding due to active smoking by the mother is unlikely.

\section{Materials and Methods}

Shanghai Municipality comprises 12 districts and 9 surrounding counties. A stratified random sample of 29 hospitals was selected from Shanghai Municipality based on birth distribution by hospital lev- els (municipal, district/county) and location (urban and rural). ${ }^{5}$ From October 1 , 1986, to September 30, 1987, each infant with birth defects born in these hospitals was recorded as a case, as was each perinatal death ( 28 weeks gestation to 7 days after birth). Each case was matched with a live-born infant free of defects born just before or after the case in the same delivery room. Specially trained nurse-interviewers, using a pretested questionnaire, interviewed mothers of cases and controls in the hospitals after delivery. Included in the interview were questions about whether the mother and father smoked and how many cigarettes he or she smoked per day. No information was collected, however, on duration of smoking by the father during pregnancy, smoking by family members, environmental tobacco smoke exposure outside the home, and certain potential confounders such as maternal and paternal height and weight. The present analysis includes only the controls $(n=1875)$. Since the effect of active maternal smoking (and, by implication, environmental tobacco smoke exposure) on prematurity is small relative to the effect on fetal growth retardation, ${ }^{3}$ and since prematurity may indicate a pregnancy at risk of low birthweight irrespective of environmental tobacco smoke exposure, we restricted the analysis to full-

Jun Zhang is with the Department of Epidemiology and Carolina Population Center, University of North Carolina at Chapel Hill. Jennifer M. Ratcliffe is with the Epidemiology Branch, Division of Biometry and Risk Assessment, National Institute of Environmental Health Sciences, Research Triangle Park, NC.

Requests for reprints should be sent to Jun Zhang, MB, Department of Epidemiology, CB \#7400, University of North Carolina, Chapel Hill, NC 27599-7400.

This paper was submitted to the Journal December 5, 1991, and accepted with revisions October 7, 1992. 


\begin{tabular}{|c|c|c|c|c|}
\hline & \multirow[b]{2}{*}{ No. } & \multicolumn{2}{|c|}{ Birthweight, g } & \multirow{2}{*}{$\begin{array}{c}\text { Environmental Tobacce } \\
\text { Smoke Exposure, \% }\end{array}$} \\
\hline & & Mean & SD & \\
\hline \multicolumn{5}{|l|}{ Sext } \\
\hline Male & 903 & 3281 & 397 & 57.8 \\
\hline Female & 882 & 3212 & 405 & 58.0 \\
\hline \multicolumn{5}{|l|}{ Parity } \\
\hline 0 & 1703 & 3246 & 402 & 57.5 \\
\hline $1+$ & 82 & 3262 & 407 & 67.1 \\
\hline \multicolumn{5}{|l|}{ Gestational age, wk* } \\
\hline $37-38$ & 382 & 3080 & 390 & 54.5 \\
\hline 39.40 & 1007 & 3261 & 392 & 59.1 \\
\hline $41-42$ & 374 & 3379 & 392 & 56.4 \\
\hline $43+$ & 22 & 3228 & 298 & 86.4 \\
\hline \multicolumn{5}{|l|}{ Maternal age, y } \\
\hline $20-24$ & 590 & 3233 & 403 & 60.4 \\
\hline $25-29$ & 905 & 3247 & 406 & 56.6 \\
\hline $30-34$ & 261 & 3288 & 390 & 57.9 \\
\hline $35+$ & 28 & 3162 & 358 & 50.0 \\
\hline \multicolumn{5}{|l|}{ Hospital location } \\
\hline Urban & 1001 & 3253 & 409 & 58.9 \\
\hline Rural & 783 & 3239 & 395 & 57.9 \\
\hline \multicolumn{5}{|l|}{ Mother's education } \\
\hline Primary school or less & 108 & 3252 & 381 & 67.9 \\
\hline Secondary school & 1098 & 3245 & 407 & 58.7 \\
\hline High school & 516 & 3249 & 401 & 56.6 \\
\hline College or more & 62 & 3241 & 388 & 38.7 \\
\hline \multicolumn{5}{|l|}{ Mother's occupation } \\
\hline Factory worker & 871 & 3255 & 402 & 61.1 \\
\hline Peasant & 457 & 3213 & 388 & 56.8 \\
\hline Service employee & 102 & 3193 & 448 & 55.9 \\
\hline \multicolumn{5}{|l|}{ Administrative or } \\
\hline Other & 212 & 3276 & 422 & 59.9 \\
\hline
\end{tabular}

term (37 weeks or more) singleton births from nonsmoking mothers $(n=1785)$. (Only one woman reported that she smoked.) Environmental tobacco smoke exposure was defined as exposure to paternal smoking. Low birthweight was defined as birthweight less than $2500 \mathrm{~g}$, and small-for-gestational-age births were classified as those involving birthweights in less than the 10th percentile for gestational age. 6 Gestational age was calculated on the basis of the last menstrual period.

In the comparison of crude birthweight between infants exposed to environmental tobacco smoke and those not exposed, Student's $t$ test and analysis of variance were used. We also used multiple linear regression and an analysis of covariance model with least squares estimates of marginal mean ${ }^{7}$ to examine effects of the potential confounders listed in Table 1. The final model controlled for gestational age, parity, maternal age, and mother's occupation. Since multiple comparisons were conducted among least squares means, the significance level was adjusted to $P=.01$. Our sample size was sufficient to detect a minimum difference of $55 \mathrm{~g}$ in birthweight and a relative risk of $\mathbf{1 . 6}$ for low birthweight between groups exposed $(n=1033)$ and not exposed $(n=752)$ to environmental tobacco smoke, with a two-sided type I error of 0.05 and a power of $80 \%$.

\section{Results}

Table 1 shows that boys were significantly higher in mean birthweight than were girls. Birthweight increased with gestational age but decreased in postterm births (43 weeks or more). Birthweight also slightly increased with increasing maternal age (20 to 34 years) but decreased among women over 35 years of age. Hospital location and maternal education were not associated with birthweight. However, infants whose mothers were service employees were somewhat lower in birthweight than were those whose mothers were employed in other occupations. Higher educated women had lower exposure to environmental tobacco smoke, as was also reflected in occupation. The proportion of mothers exposed to environmental tobacco smoke was similar across other maternal characteristics, with the exception of mothers with postterm infants $(n=22)$.

The unadjusted mean birthweights for nonexposed and exposed infants were $3262 \mathrm{~g}$ and $3236 \mathrm{~g}$, respectively. This difference of $26 \mathrm{~g}$ was not significant $(t=1.33, P=.18)$. Multiple linear regression, including father's smoking (yes or no) and controlling in the final model for parity, maternal age, gestational age, and mother's occupation, indicated that infants exposed to environmental tobacco smoke weighed, on average, $30 \mathrm{~g}$ less at birth than nonexposed infants (95\% $C I=-7,66)$. When we examined the relationship between the reported number of cigarettes smoked by the father and infant's birthweight, we found a nonlinear dose-response relationship (Table 2). Although paternal smoking of up to $19 \mathrm{cig}$ arettes per day was associated with a progressive decrease in birthweight, smoking of $\mathbf{2 0}$ or more cigarettes per day was associated with a slightly increased birthweight of $32 \mathrm{~g}$ compared with nonexposed infants (linear trend test, $P>.5$ ). The proportions of low-birthweight and small-forgestational-age births were slightly higher in the exposed group but were not statistically significant ( $\chi^{2}$ test, both $P \mathrm{~s}>.5$ ).

\section{Discussion}

The present study shows a mean $30-g$ decrease in birthweight among infants exposed to environmental tobacco smoke. This decrease is similar to that reported by Chen et al, 8 who used the same source population as in the present study and who also excluded malformations; they found a nonsignificant birthweight difference of $12 \mathrm{~g}$ between infants exposed and not exposed to environmental tobacco smoke. In several prospective studies, nonsignificant reductions in birthweight from 11 to $66 \mathrm{~g}$ were reported among nonsmoking women exposed to environmental tobacco smoke; these reductions represented approximately $7 \%$ to $27 \%$ of the observed decrease in birthweight due to maternal active smoking.9-14 However, these findings contrast with some studies using paternal smoking as the only measure of environmental tobacco smoke ex- 
posure, in which decreases in mean birthweights of over $200 \mathrm{~g}$ were reported among exposed subjects compared with nonexposed controls. ${ }^{4}$ A review of Hood attributed these "implausibly large" reductions in birthweight to the less optimal study design and the inclusion of smoking women. ${ }^{4}$

It should be noted that the estimation of environmental tobacco smoke exposure in our study was limited. It is clear that reliance on the mother's report of the number of cigarettes smoked by the father results in a relatively crude estimate of the mother's actual exposure. Those fathers who smoked more cigarettes per day overall may not necessarily have smoked proportionately more at home. Furthermore, no data were available on smoking by other members of the household or other sources of exposure. If there is an effect of environmental tobacco smoke exposure on birthweight and if a proportion of births classified as nonexposed were in fact exposed, this could result in an artificially low mean birthweight for the nonexposed group and, consequently, dilute the difference in birthweight between exposed and nonexposed infants. It is unlikely, however, that the number of cigarettes the father smoked was underreported. Although it is not yet commonly acceptable in Shanghai for young women to smoke, male smoking is considered "normal." In addition, little public attention has been paid to potentially harmful effects of environmental tobacco smoke exposure during pregnancy. Furthermore, the male smoking prevalence reported by wives in our study $(58 \%)$ was similar to that in a previous report $(57 \%$ between 20 and 39 years of age). ${ }^{2}$

In the present study, a nonmonotonic dose-response relationship between environmental tobacco smoke exposure and birthweight was observed. Since the confidence intervals around point estimates for birthweights at each level of paternal smoking overlap considerably (Table 2), the lack of a linear trend could be due to chance or to inaccuracy in ascertainment of the mother's exposure. It is also possible that heavy smoking by the father is associated with an unknown confounding variable for which data were not collected in the original study but that is associated with higher birthweight (e.g., parental height and weight). Furthermore, longterm exposure of the mother to higher levels of environmental tobacco smoke might be sufficient to induce hepatic and placental mixed function oxidases, which then metabolize nicotine and possibly other

TABLE 2 - Environmental Tobacco Smoke Exposure and Fetal Growth

Father's

Smoking,

Cigarettes

per Day

(nean

Mean $95 \%$ Confidence Interval ${ }^{2}$

Low

Small for Birthweight, \% Gestational Age, \%

\begin{tabular}{c|c|c}
\hline None & 752 & 3181 \\
$1-4$ & 160 & 3148 \\
$5-9$ & 190 & 3119 \\
$10-14$ & 339 & 3123 \\
$15-19$ & 56 & 3119 \\
$20+$ & 288 & $3213_{b}$
\end{tabular}

\begin{tabular}{l|}
2995,3367 \\
2954,3342 \\
2927,3311 \\
2933,3313 \\
2909,3329 \\
3025,3401 \\
\hline
\end{tabular}

$\left.\begin{array}{l}2.26 \\ 2.48 \\ 2.63 \\ 2.65 \\ 0.00 \\ 2.43\end{array}\right\} 2.42$

Note. The difference between entries with different subscripts is significant $(P<.01)$.

'Least squares means adjusted for gestational age, parity, maternal age, and mother's occupation.

smoke components and embryotoxins at a faster rate than among women with less exposure. It is known that active smokers metabolize nicotine at a faster rate than those exposed to environmental tobacco smoke or nonsmokers 15,16 and that the placental enzymes that metabolize xenobiotic compounds are induced by active smoking 17 and thus, possibly, by high levels of exposure. This might result in a nonlinear dose-response relationship between exposure to environmental tobacco smoke and birthweight. However, lack of empirical evidence makes this hypothesis uncertain.

One final point should be emphasized. In the present study and virtually all previous studies, at least part of the pregnant mother's exposure to environmenta! tobacco smoke was contributed by the father's smoking. Read and Stanley found that paternal smoking was an independent risk factor for recurrent small-for-gestational-age term births among nonsmoking mothers. ${ }^{18}$ Evidence from animal and human studies of exposure of males to certain chemicals (e.g., alcohol ${ }^{19,20}$ ), followed by mating with unexposed females, also suggests that a decrease in birthweight due to an effect via the paternal genome is biologically plausible. Although no experimental data are available for tobacco smoke components, the possibility that a decrease in birthweight may be due to a sperm-mediated effect cannot be excluded.

The question arises as to the statistical and clinical significance of a modest (30-g) reduction in mean birthweight and a slight increase in the proportion of lowbirthweight and small-for-gestational-age infants. Since over $50 \%$ of pregnant women in Shanghai (and elsewhere in China) are exposed to environmental tobacoo smoke, even a modest downward shift in the birthweight distribution, if caused by such exposure, may be clinically relevant in the overall population. The control of smoking in China is very important in terms of the "impending catastrophe" not only for adult health, ${ }^{1}$ but also for fetal and child health. ${ }^{21,22}$

\section{References}

1. Yu JJ, Mattson ME, Boyd GM, et al. A comparison of smoking patterns in the People's Republic of China with the United States: an impending health catastrophe in the middle kingdom. JAMA. 1990;264: 1575-1579.

2. Deng J, Gao YT, Jiao SM, et al. The prevalence of cigarette smoking habit among 110,000 adult residents in Shanghai urban area. Chin J Prev Med. 1985;19:271-274.

3. Kramer MS. Determinants of low birth weight: methodological assessment and meta-analysis. Bull WHO. 1987;65:663737.

4. Hood RD. An assessment of potential effects of environmental tobacco smoke on prenatal development and reproductive capacity. In: Ecobichon D, Wu J, eds. Environmental Tobacco Smoke: Proceedings of the International Symposium at McGill University 1989. Montreal, Quebec, Canada: Lexington Books; 1990:241-269.

5. Zhang J, Cai WW, Chen H. Perinatal mortality in Shanghai: 1986-87. Int J Epidemiol. 1991;20:958-963.

6. Zhang BL. Intrauterine growth as estimated from liveborn birthweight data in China. Chin J Pediatr. 1989;27:316.

7. SAS/STAT User's Guide. Release 6.03 Edition. Cary, NC: SAS Institute Inc; 1988:549-640.

8. Chen Y, Pederson LL, Lefcoe NM. Passive smoking and low birthweight. Lancet. 1989;ii:54-55. Letter.

9. Martin TR, Bracken MB. Association of low birth weight with passive smoking exposure in pregnancy. Am J Epidemiol. 1986;124:633-642.

10. Brooke OG, Anderson HR, Bland JM, Peacock JL, Stewart CM. Effects on birthweight of smoking, alcohol, caffeine, socioeconomic factors and psychosocial stress. Br Med J. 1989;298:795-801.

11. Ahlborg G, Bodin L. Tobacco smoke ex- 
posure and pregnancy outcome among working women. Am J Epidemiol. 1991; 133:338-347.

12. Ogawa $H$, Tominaga $S$, Hori $K$, Noguchi K, Kanou I, Matsubara M. Passive smoking by pregnant women and fetal growth. $J$ Epidemiol Community Health. 1991;45: 164-168.

13. Mathai M, Skinner A, Lawton $K$, Weindling AM. Maternal smoking, urinary cotinine levels and birthweight. Aust NZ J Obstet Gynaecol. 1990;30:33-36.

14. Lazzaroni F, Bonassi S, Manniello E, et al. Effect of passive smoking during pregnancy on selected perinatal parameters. Int $J$ Epidemiol. 1990;19:960-966.

15. Sepkovic DW, Haley NJ, Hoffmann D.
Elimination from the body of tobacco products by smokers and passive smokers. JAMA. 1986;256:863.

16. National Research Council. Environmental Tobacco Smoke. Measuring Exposures and Assessing Health Effects. Washington, DC: National Academy Press; 1986.

17. Manchester DK, Parker NB, Bowman CM. Maternal smoking increases xenobiotic metabolism in placenta but not umbilical vein endothelium. Pediatr Res. 1984; 18:1071-1075.

18. Read AW, Stanley FJ. A comparison of recurrent and isolated small-for-gestational-age term births. Pediatr Perinat Epidemiol. 1991;5:138-156.
19. Mankes RF, LeFevre R, Benitz KF, et al. Paternal effects of ethanol in the LongEvans rat.J Toxicol Environ Health. 1982; 10:871-878.

20. Little RE, Sing CF. Father's drinking and infant birthweight report of an association. Teratology. 1987;36:59-65.

21. Chen Y, Li WX, Yu SZ. Influence of passive smoking on admission for respiratory illness in early childhood. Br Med J. 1986; 293:303-306.

22. Chen Y, Li WX, Yu SZ, Qian WH. ChangNing epidemiological study of children's health I: passive smoking and children's respiratory diseases. Int $J$ Epidemiol. 1988; 17:348-355.

\section{New Report from APHA: Tuberculosis and HIV Disease}

The American Public Health Association's Special Initiative on AIDS has recently published the ninth report in its series on acquired immunodeficiency syndrome (AIDS), prepared under the auspices of the APHA AIDS Working Group. The new report is entitled "Tuberculosis and HIV Disease."

This report summarizes current knowledge about the manifestations and progression of tuberculosis (TB) infection and disease and the interaction of TB with human immunodeficiency virus (HIV) infection. The scope of the problem of TB in the United States is reviewed, and strategies for the prevention, detection, and treatment of TB infection and disease are examined. Some of the policy issues associated with the current US rise in TB rates are also discussed.

To date, the series includes these reports:

Report 1: Casual Contact and the Risk of HIV Infection, 2nd ed.

Report 2: Contact Tracing and Partner Notification

Report 3: Illicit Drug Use and HIV Infection, 2nd ed.

Report 4: HIV Antibody Testing

Report 5: Public Health Implications of PCP Prophylaxis

Report 6: Pediatric HIV Infection

Report 7: Public Health Implications of Earty Intervention in HIV Disease

Report 8: Women and HIV Disease

Report 9: Tuberculosis and HIV Disease

Each report is $\$ 2.45$ per copy for APHA members, $\$ 3.50$ for nonmembers. The complete nine-report series is $\$ 19.95$ for APHA members, $\$ 28.50$ for nonmembers. Orders must be prepaid. Order from: American Public Health Association, Publication Sales, Department 5037, Washington, DC 200615037; tel. (202) 789-5667. 